This item was submitted to Loughborough's Research Repository by the author.

Items in Figshare are protected by copyright, with all rights reserved, unless otherwise indicated.

\title{
Strength prediction for bi-axial braided composites by a multi-scale modelling approach
}

PLEASE CITE THE PUBLISHED VERSION

http://dx.doi.org/10.1007/s10853-016-9901-z

\section{PUBLISHER}

(C) Springer

VERSION

AM (Accepted Manuscript)

\section{PUBLISHER STATEMENT}

This work is made available according to the conditions of the Creative Commons Attribution-NonCommercialNoDerivatives 4.0 International (CC BY-NC-ND 4.0) licence. Full details of this licence are available at: https://creativecommons.org/licenses/by-nc-nd/4.0/

\section{LICENCE}

CC BY-NC-ND 4.0

\section{REPOSITORY RECORD}

Wang, Chen, Yucheng Zhong, P.F. Bernad Adaikalaraj, Xianbai Ji, Anish Roy, Vadim V. Silberschmidt, and Zhong Chen. 2019. "Strength Prediction for Bi-axial Braided Composites by a Multi-scale Modelling Approach". figshare. https://hdl.handle.net/2134/21082. 


\title{
Strength prediction for bi-axial braided composites by a multi-scale modelling approach
}

\author{
Chen Wang ${ }^{1,2,3}$, Yucheng Zhong ${ }^{4}$, P. F. Bernad Adaikalaraj ${ }^{4}$, Xianbai $\mathrm{Ji}^{4}$, Anish Roy ${ }^{3}$, \\ Vadim V. Silberschmidt ${ }^{3}$, and Zhong Chen ${ }^{1,4, *}$ \\ ${ }^{1}$ School of Materials Science and Engineering, Nanyang Technological University, 50 Nanyang Avenue, Singapore 639798, \\ Singapore \\ ${ }^{2}$ Institute for Sports Research, Nanyang Technological University, 50 Nanyang Avenue, Singapore 639798, Singapore \\ ${ }^{3}$ Wolfson School of Mechanical and Manufacturing Engineering, Loughborough University, Leicestershire LE11 3TU, UK \\ ${ }^{4}$ Temasek Laboratories@NTU, 50 Nanyang Drive, Singapore 637553, Singapore
}

\begin{abstract}
Braided textile-reinforced composites have become increasingly attractive as protection materials thanks to their unique inter-weaving structures and excellent energy-absorption capacity. However, development of adequate models for simulation of failure processes in them remains a challenge. In this study, tensile strength and progressive damage behaviour of braided textile composites are predicted by a multi-scale modelling approach. First, a microscale model with hexagonal arrays of fibres was built to compute effective elastic constants and yarn strength under different loading conditions. Instead of using cited values, the input data for this micro-scale model were obtained experimentally. Subsequently, the results generated by this model were used as input for a meso-scale model. At meso-scale, Hashin's 3D with Stassi's failure criteria and a modified Murakami-type stiffness-degradation scheme was employed in a user-defined subroutine developed in the general-purpose finiteelement software Abaqus/Standard. An overall stress-strain curve of a mesoscale representative unit cell was verified with the experimental data. Numerical studies show that bias yarns suffer continuous damage during an axial tension test. The magnitudes of ultimate strengths and Young's moduli of the studied braided composites decreased with an increase in the braiding angle.
\end{abstract}

\section{Introduction}

Braided textile-reinforced composites have received considerable attention in the recent years as protection materials for various applications, including sports products (e.g. helmets and shin guards) [1, 2]. Such composites combine high structural stability with low cost, excellent damage tolerance and energy absorption thanks to yarn interlacing. The ease of incorporating different types of yarns enables manufacture of 
composites with a wide range of overall mechanical and physical properties [3]. To aid product optimization at the design stage, numerical models need to be developed, which, in turn, require a thorough understanding of mechanical responses and energy-dissipation mechanisms of braided composites.

To date, only limited research has been conducted on prediction of mechanical properties and damage evolution in braided composites [4]. Numerical tools such as finite-element (FE) analysis were used to solve nonlinear dynamic problems associated with composite failure [5-12]. Ivanov et al. [7] investigated failure of triaxial braided composites using the degradation scheme of Murakami-Ohno and the damage evolution law of Ladeveze. Xiao et al. [8] employed a sub-cell FE representation of microstructure of textile composites to predict their strength. Fang et al. [9] analysed a representative volume cell (RVC) of braided composites with a damage evolution model controlled by fracture energy of constitutive materials. Prabhakar et al. [10] considered kinking and splitting for fibre tows under compressive load. Binienda et al. [11] studied an overall stress-strain curve of $0^{\circ} / \pm 60^{\circ}$ 2D triaxially braided composites with an advanced shell-element model. In these studies, the meso-scale modelling approach was widely used to obtain stress (and strain) distributions throughout the braided structure. Song et al. [12] analysed an effect of a number of unit cells on compressive failure of 2D tri-axial braided composites. However, meso-scale modelling is rather challenging and should be attempted based on three aspects [13]. First, the unitcell geometry should be realistic, since the dimensions of yarn play an important role in deformation and damage behaviour of the model. Second, effective properties of yarn should be accurately determined. Third, the modelling strategy implies that the details of the physics below the yarn-level cannot be recovered.

A more advanced and adequate scheme, capturing physics at the micro-level, is a multi-scale scheme that can be used to link microscopic failure effects with mesoscopic behaviour of the braided composites [14-18]. Consequently, homogenized mechanical properties of yarns and ultimate strength of the composite can be predicted more effectively using a multi-scale modelling approach. For instance, Bednarcyk et al. [19] utilized a micro-mechanics theory known as Generalized Method of Cells to represent non-linear behaviour of plain weavereinforced polymeric composites. Zhang et al. [20] investigated a free-edge effect and progressive damage of a single-layer braided composite, using simplified
Hashin's 2D failure criteria. Zhang et al. [21, 22] presented a multi-scale computational model used to predict deformation, damage and failure responses of $3 \mathrm{D}$ textile composites subjected to three-point bending. $\mathrm{Xu}$ et al. [23] applied a Micro-mechanics of Failure theory to predict tensile strength of braided structures and damage initiation in yarns. It is clear that either classical failure criteria or newly developed mechanical theory were incorporated into multi-scale schemes for strength prediction for braided composites. However, reliability and accuracy of such schemes are still debatable [23-25]. The damage evolution law of Ladeveze is attractive for UD composites because of its simplicity, but it needs modification when applying to braided composites. No criterion is universally accepted by designers as adequate under general loading conditions, since some of the adopted classical criteria are not capable to capture initiation of damage of braided composites effectively. Moreover, some failure modes such as fibre splitting, matrix cracking or interface failure are not presented adequately [26].

The aim of this study is to attempt a multi-scale modelling framework accounting for the underlying physical mechanisms that drive deformation and damage in the composite under static tensile loading states. In this study, a micro-scale model was first built with hexagonal arrays of fibres to obtain effective elastic constants and strengths of yarns under different loading conditions. The input data for the micro-scale model were experimentally measured in our previous work $[27,28]$. The results of micro-scale modelling were used as input for material properties of the meso-scale model. Hashin's 3D and Stassi's failure criteria were presented with a stiffnessdegradation model in a user-defined subroutine for the FE software Abaqus/Standard. The overall stress-strain curve obtained with the meso-scale model was correlated with experimental data. Finally, the predictive capability of the developed model was illustrated with some case studies.

\section{Multi-scale modelling approach}

\section{Geometric representative unit cells}

Micro-scale modelling aims at obtaining effective properties of the yarn of a braided composite. Microstructure of the yarn is similar to that of a 
lamina in terms of fibre, matrix and interface. In our micro-scale model, fibres were arranged hexagonally considering high-fibre volume fractions in fibre bundles of braided composites. Previous studies [29, 30] demonstrated that predictions of elastic moduli and strengths based on hexagonal and random arrangements were very similar Specifically, this volume fraction was assumed as 0.8 herein with a representative unit cell (RUC) as depicted in Fig. 1, in which $2 \pi r^{2} / a b=0.8$. Here, $a$ and $b$ are the length and width of the RUC, respectively, while $r$ is the radius of the carbon fibre.

A bi-axial braided textile preform consists of interlaced $+\theta$ and $-\theta$ bias yarns [23, 31] (Fig. 2). In creating unit cells, these components were modelled separately using SolidWorks ${ }^{\mathrm{TM}}$. Bias yarns were created by sweeping a cross-section with an elliptical shape along a predefined undulating path. From a careful observation of a complex microstructure of a braided textile, a repeating unit can be identified as shown in Fig. 2a, b. The geometric parameters marked in Fig. 2 include the braiding angle $\theta$, width and thickness of braiding yarns $w$ and $t$, respectively, the distance between neighbouring yarns $\varepsilon$ and the gap between the interlacing yarns. In this work, all the dimensions were measured for the real braided architecture. The width and thickness of yarns were 3 and $0.314 \mathrm{~mm}$, respectively. A cross-section of the yarn was modelled as elliptical shape, with the value of $\varepsilon$ and the gap between positive and negative bias tows set as 0.2 and $0.05 \mathrm{~mm}$. The global fibre volume fractions $\left(V_{\mathrm{f}}\right)$ of the unit cell were set to be $50 \%$ for all the braiding angles; based on it, dimensions of the matrix block were chosen.
To facilitate a subsequent FE analysis, the diamond braided textile unit cell was further merged with a matrix block as a composite volume element-a

(a)

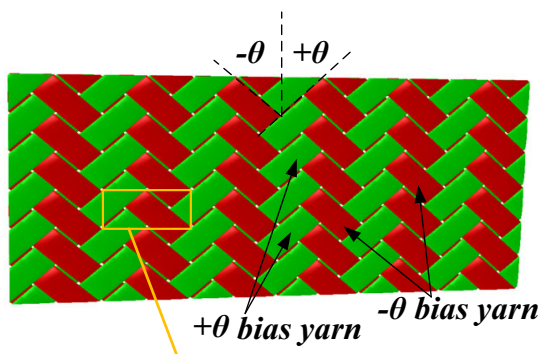

(b)

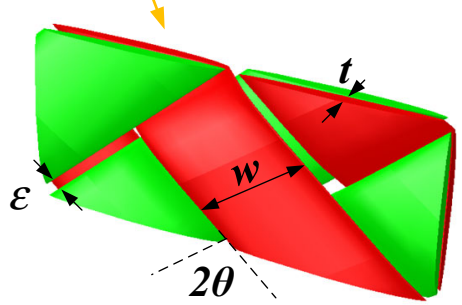

(c)

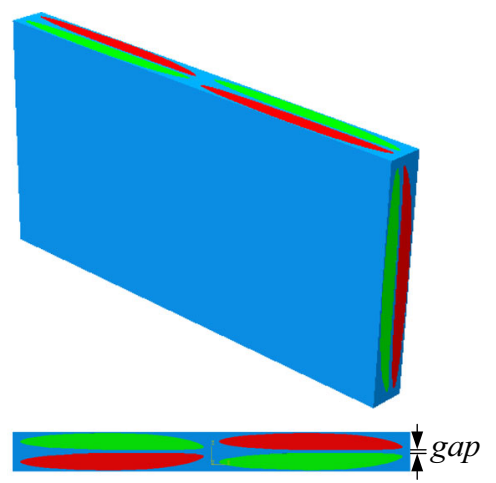

Figure 2 Architecture of bi-axial braided textiles (a); meso-scale model representation (b); the RUC of composite (c); and its side view of RUC (d).
Figure 1 Geometry of hexagonal micro-unit cell.

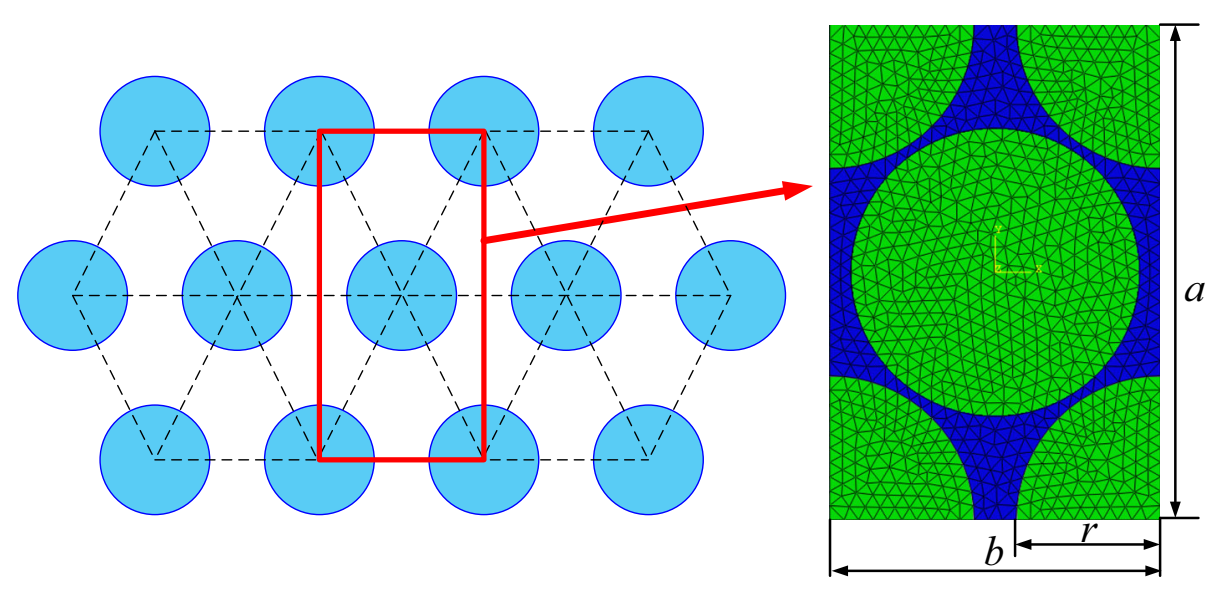


meso-scale RUC, as shown in Fig. $2 \mathrm{c}$ and d. Such RUC represents a repeating part of microstructure of the modelled specimen. Since bias yarns do not terminate at the edges parallel to the longitudinal direction, they interlock with each other to transmit an applied load.

\section{Mesh generation and boundary conditions}

Four-node tetrahedron elements (C3D4) were used to mesh the micro-scale unit cell, including both fibre and matrix (Fig. 1). Zero-thickness cohesive elements (COH3D8) were located at the fibre/epoxy interfaces. As a unit cell is a small RUC of the yarn, the use of periodic boundary conditions (PBCs) devised by Xia et al. [32] is essential. In terms of the unit cell studied here, the PBCs and minimization of mesh mismatches were achieved through increasing the number of unit cells analysed in a single simulation, while merging mismatched nodes on contacting faces. According to our previous work [31], seven independent boundary conditions (BCs) in the form of uniform displacements were specified to obtain the material properties of fibre tows, as shown in Fig. 3. Since carbon fibres are a transversely isotropic material, subscript 1 denotes fibre direction and 2 and 3 denote transverse directions. A global coordinate system was employed for the whole model.

For yarns and the pure matrix block in the mesoscale unit cell, four-node tetrahedron elements (C3D4) were used to discretise the complex yarn architecture inside the RUC (Fig. 4a). The mesh density should be sufficient for an adequate introduction of geometry of the undulated tow. Since the pure matrix region between the yarns was very thin ( $\sim 0.02-0.05 \mathrm{~mm}$ ), a number of elements required to attain acceptable mesh quality was relatively high compared to that for yarns. A mesh-convergence study was carefully carried out to avoid any meshdependent results. Unlike a micro-scale model, a simple non-periodic boundary condition was used in meso-scale RUCs to predict ultimate strengths of the braided composite as shown in Fig. 4b. To apply PBCs, opposite sides of the model must have identical nodal coordinates and a constraint equation should be used to tie each node pair. However, this becomes difficult to impose as node pairs are not always placed symmetrically on either side because of an irregular mesh used to discretise the model. Instead, in our modelling, the lateral sides of the unit cell were left free to move, while a displacement boundary condition was applied at the top surface of the unit cell and the bottom surface was constrained with a pin boundary condition (Fig. 4b). A detailed comparison studies [33, 34] of PBCs and non-periodic boundary conditions for braided composites show that the difference was minimal in case of uniaxial loading conditions. This justifies the chosen modelling approach.

In the meso-scale model, the matrix material was assumed to be isotropic and braiding yarns were transversely isotropic. Assigning material orientation
Figure 3 Boundary conditions of micro-scale unit cell for longitudinal properties (a), transverse properties (b), in-plane shear (c), out-of-plane shear (d), and Poisson ratio (e).

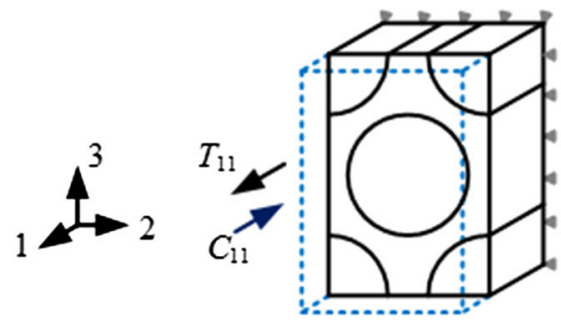

(a)

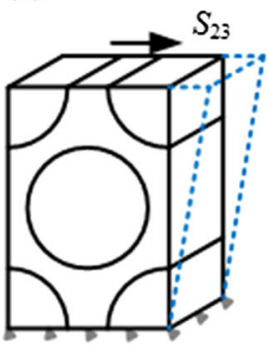

(d)

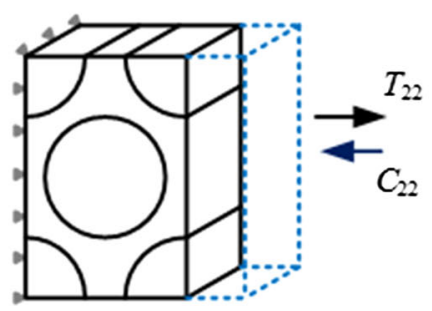

(b)

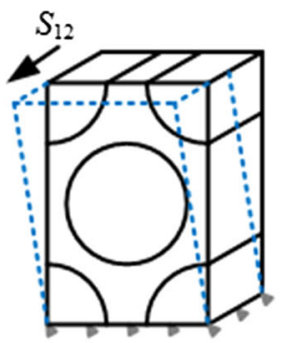

(c)

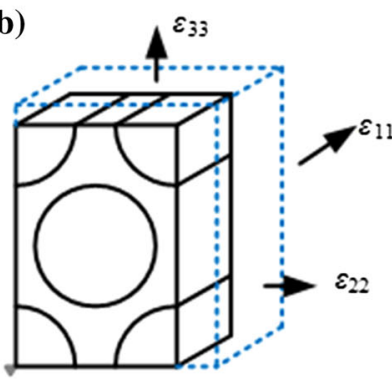

(e) 
Figure 4 Meshing unit cell of bi-axial braided composite

(a) and displacement-

controlled boundary condition

(b). (a)

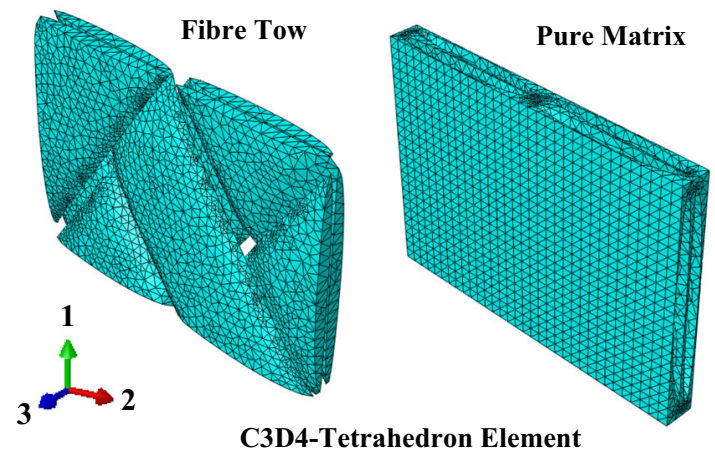

(b)

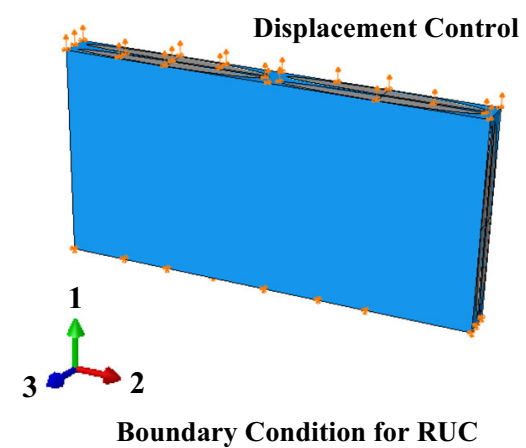

to yarns is one of the important steps because of yarn's undulations inside the unit cell. In this work, orientation of yarns was assigned discretely, defining a normal surface and principal axis (fibre direction). With this method, undulations and tilt regions were assigned with precise material orientation at all locations of the mesh in comparison with global coordinate system, as shown in Fig. 5.

\section{Failure criteria and stiffness-degradation model}

In the micro-scale model, a maximum stress failure criterion was deemed appropriate in describing damage initiation of carbon fibres, as

$\sigma_{\mathrm{f}} \geq X_{\mathrm{fT}}$ or $\left|\sigma_{\mathrm{f}}\right| \geq X_{\mathrm{fC}}$,

where $X_{\mathrm{T}}$ and $X_{\mathrm{C}}$ are the tensile and compressive strengths, respectively, the subscript $f$ denotes carbon fibre, and $\sigma_{\mathrm{f}}$ is the normal stress component along the longitudinal fibre direction. At fibre failure (Eq. 1), the Young's modulus was reduced to zero instantaneously [35]. It should be noted that failure mechanisms of fibre tows under longitudinal compression are quite complicated [36]. In order to obtain consistent values of the longitudinal modulus under tension and compression, that strong bonding between fibres and matrix was assumed leading to fibre rupture rather than buckling or kinking.

A modified von Mises criterion (the Stassi's criterion), which accounts for two strength parameters, was employed to capture damage initiation in pure matrix both for micro- and meso-scale models. Although the matrix in the unit cell was considered isotropic, tensile failure strength of epoxy matrix is generally lower than the compressive one. This is due to the influence of hydrostatic pressure (a first invariant of the stress tensor) besides deviatoric stress components on the tensile strength. Christensen [37] modified the Stassi's criterion for materials with different strengths in compression and tension as

$\left[\frac{1}{X_{\mathrm{mT}}}-\frac{1}{X_{\mathrm{mC}}}\right] 3 P+\frac{1}{X_{\mathrm{mT}} X_{\mathrm{mC}}} \sigma_{\mathrm{vm}}^{2} \leq 1$,

where $P$ and $\sigma_{\mathrm{vm}}$ are the hydrostatic pressure and von Mises stress, respectively. Subscript $m$ represents epoxy matrix in this paper.

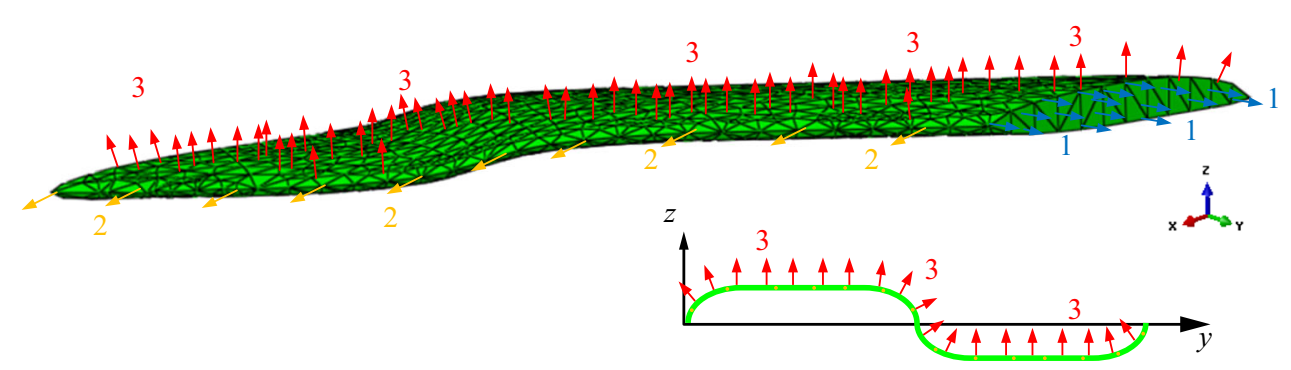

Figure 5 Segmentation of individual bias yarns and local coordinate systems (Blue arrows indicate local direction of "1"; yellow arrows indicate local direction of " 2 "; and red arrows indicate local direction of " 3 "). 
Zero-thickness cohesive elements were utilized to simulate the fibre tow interface in the micro-scale model. The response of these elements was governed by a typical bilinear traction-separation law [36]; a quadratic nominal stress criterion was used to describe interfacial damage initiation. Damage evolution was defined based on the fracture energy. Exponential softening behaviour was utilized. The dependency of fracture energy on mixed fracture modes was expressed by a widely used Benzeggagh and Kenane formulation [11]. The same fracture energy value was assumed for each mode of interfacial failure.

The Hashin's 3D failure criteria were applied to define damage initiation of fibre yarns in the mesoscale RUCs. The failure criteria are usually established in terms of mathematical expressions using the material strengths, with the consideration of different failure modes of the composite constituents. These criteria have an advantage of being capable to predict failure modes and are therefore suitable for progressive damage analysis. Hashin [38] proposed two failure modes associated with the fibre tow and the matrix, considering both tension and compression:

Fibre failure in tension : $\left(\sigma_{1}>0\right) \quad\left(\frac{\sigma_{1}}{X_{\mathrm{T}}}\right)^{2}+\frac{\tau_{12}^{2}+\tau_{13}^{2}}{\left(S_{12}\right)^{2}}=1$

Fibre failure in compression : $\left(\sigma_{1}<0\right) \quad-\sigma_{1}=X_{\mathrm{C}}$

Matrix failure in tension : $\left(\sigma_{2}+\sigma_{3}>0\right)$

$$
\left(\frac{\sigma_{2}+\sigma_{3}}{Y_{\mathrm{T}}}\right)^{2}+\frac{\tau_{23}^{2}-\sigma_{2} \sigma_{3}}{\left(S_{23}\right)^{2}}+\frac{\tau_{12}^{2}+\tau_{13}^{2}}{\left(S_{12}\right)^{2}}=1
$$

Matrix failure in compression : $\left(\sigma_{2}+\sigma_{3}<0\right)$

$$
\begin{aligned}
& {\left[\left(\frac{Y_{\mathrm{C}}}{2 S_{23}}\right)^{2}-1\right] \frac{\sigma_{2}+\sigma_{3}}{Y_{\mathrm{C}}}+\left(\frac{\sigma_{2}+\sigma_{3}}{2 S_{23}}\right)^{2}+\frac{\tau_{23}^{2}-\sigma_{2} \sigma_{3}}{\left(S_{23}\right)^{2}}} \\
& +\frac{\tau_{12}^{2}+\tau_{13}^{2}}{\left(S_{12}\right)^{2}}=1
\end{aligned}
$$

Here $\sigma_{i}$ is the normal stress component in $i$ direction; $\tau_{i j}$ are the components of the shear stress; $X$ and $Y$ denote the longitudinal and transverse strengths and $S_{i j}$ are the components of the shear strength of the fibre tow.

Rupture of the yarn is generally known to be a sudden event without any hardening effects. Therefore, in the yarn, once the critical stress level was predicted using the Hashin's failure index [38], an instantaneous degradation scheme was applied depending on the mode of failure. Attractive aspects of these schemes are simplicity in implementation and computational efficiency for large problems, since the damage variable is defined as a constant, whereas in the gradual degradation scheme, the damage variable is a function of evolving solution-dependent variables, thus leading to a large computation time.

According to the Hashin's 3D criteria, failure modes were identified in both fibre and matrix either in tension or compression. In case of fibre failure in compression or tension, all the elastic constants were instantly reduced to a near-zero value (drop to $0.1 \%$ of the initial herein). It should be noted that transverse stiffness is much lower than longitudinal stiffness values. As a consequence, any changes in the level of transverse stiffness would not affect the fibre strength. For a matrix-failure case, tension and compression are separated to account for different failure behaviours under transverse loading. The degradation of shear moduli was modified based on the Ladeveze model, in which the shear moduli reduction is regards as too sharp and arbitrary [7].

The Murakami-type degradation model usually involves reducing the material properties in a single step once the failure criterion is fulfilled. However, to maintain numerical stability, the stiffness matrix must be positive. Therefore, in the stiffness matrix of a $3 \mathrm{D}$ orthotropic material, it is required that $E_{1}, E_{2}, E_{3}$, $G_{12}, G_{13}, G_{23}, 1-v_{23} v_{32}, 1-v_{13} v_{31}, 1-v_{12} v_{21}$ and $\Delta$ are non-negative. In addition, the material properties should satisfy a Maxwell-Betti reciprocal theorem, i.e. $\frac{v_{i j}}{E_{i}}=\frac{v_{j i}}{E_{j}}$ and $\left|v_{i j}\right|<\sqrt{\frac{E_{i}}{E_{j}}}$ for $i, j=1,2,3$ and $i \neq j . \varepsilon, E$, $G$ and $v$ herein are strain, the elastic modulus, the shear modulus and the Poisson's ratio in corresponding principal directions.

In summary, a flow chart, depicting all the steps involved in the FE analysis process to perform progressive failure analysis of yarns, is presented in Fig. 6. Initially, a solid model of the unit cell was developed using SolidWorks CAD package. Then, the $3 \mathrm{D}$ unit-cell geometry was imported into Abaqus 
Figure 6 Flow chart for micro-/meso-scale damage analysis.

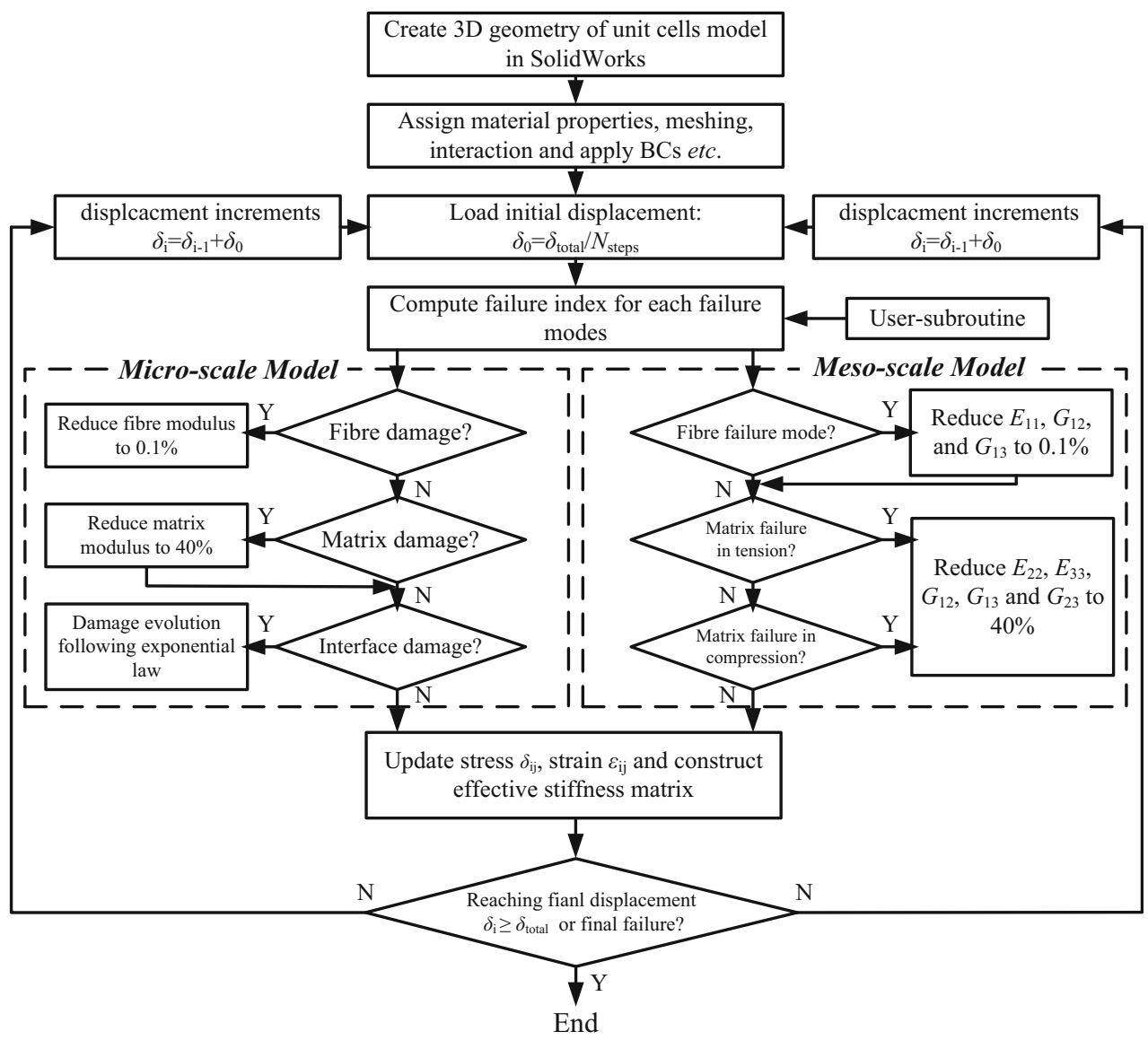

CAE. In the Abaqus pre-processor, material properties and orientation, boundary conditions and meshing were defined. Then, a non-linear behaviour of the unit cell under displacement was simulated.

The developed micro- and meso-scale models were implemented separately. The simulation procedure in both situations was similar. First, for each element, different modes of failure were captured using a failure index from the solution from the previous time increment. Second, if any of the failure indices reach a value of one, elastic constants were reduced in a single step according to the mode of failure, and the global stiffness matrix was assembled from effective stiffness matrices. This global system was solved to obtain nodal force vectors. Finally, this process was repeated until the specified total displacement condition was satisfied.

The damage-initiation criteria with the propertydegradation model were implemented into the Abaqus implicit solver with the use of the user-defined field subroutine (USDFLD). For each small displacement increment, the elastic stiffness matrix was calculated according to the hypothesis of strain equivalence in continuum damage mechanics.

\section{Materials and material properties}

The carbon fibre tested and modelled in this work was a PAN (Polyacrylonitrile)-based AKSAca A-42 carbon fibre with bulk density of $1.78 \mathrm{~g} / \mathrm{cm}^{3}$ and yield of $800 \mathrm{~g} / \mathrm{km}$, respectively. The fibre diameter was determined, by measuring 20 fibres, to be $7.3 \pm 0.4 \mu \mathrm{m}$. The matrix material was Bakelite ${ }^{\circledR}$ EPR-L20 epoxy resin. Bakelite ${ }^{\circledR}$ EPR-L20 epoxy was mixed with EPH-960 hardener at the weight ratio of 100:35, and the mixture was then degassed for approximately $30 \mathrm{~min}$ before curing for 24 -h at room temperature and $15 \mathrm{~h}$ at $60{ }^{\circ} \mathrm{C}$. The material properties of fibres, epoxy and their interface were 
Table 1 Properties of A-42 carbon fibres for micro-scale model [27]

\begin{tabular}{lc}
\hline Material Property & Value \\
\hline Longitudinal modulus, $E_{\mathrm{f} 1}(\mathrm{GPa})$ & 239.5 \\
Transverse modulus, $E_{\mathrm{f} 2}=E_{\mathrm{f} 3}(\mathrm{GPa})$ & 13.4 \\
Longitudinal shear modulus, $G_{\mathrm{f} 12}=G_{\mathrm{f} 13}(\mathrm{GPa})$ & 6.81 \\
Transverse shear modulus, $G_{\mathrm{f} 23}(\mathrm{GPa})$ & 4.8 \\
Major Poisson's ratio, $v_{\mathrm{f} 12}=v_{\mathrm{f} 13}$ & 0.2 \\
Minor Poisson's ratio, $v_{\mathrm{f} 23}$ & 0.25 \\
Tensile strength of yarns in fibre direction, $X_{\mathrm{ft}}(\mathrm{GPa})$ & 3.16 \\
Compressive strength of yarns in fibre direction, $X_{\mathrm{fc}}$ & 728.8 \\
$(\mathrm{MPa})$ & \\
\hline
\end{tabular}

Table 2 Properties of epoxy for multi-scale model [27]

\begin{tabular}{lr}
\hline Material Property & \multicolumn{1}{c}{ Value } \\
\hline Elastic modulus, $E_{\mathrm{m}}(\mathrm{GPa})$ & 3.30 \\
Elastic Poisson's ratio, $v_{\mathrm{m}}$ & 0.35 \\
Tensile strength, $X_{\mathrm{mT}}(\mathrm{MPa})$ & 60.18 \\
Compression strength, $X_{\mathrm{mC}}(\mathrm{MPa})$ & 107.37 \\
Shear strength, $S_{\mathrm{m}}(\mathrm{MPa})$ & 41.03 \\
\hline
\end{tabular}

Table 3 Properties of carbon fibre/epoxy interface for micro-scale model [28]

\begin{tabular}{ll}
\hline Material property & Value \\
\hline Interfacial shear strength, $t_{\mathrm{I}}(\mathrm{MPa})$ & 28.12 \\
Interface fracture energy, $G_{\mathrm{Ic}}\left(\mathrm{J} \mathrm{m}^{-2}\right)$ & 12.9 \\
\hline
\end{tabular}

characterized experimentally in our previous studies $[27,28]$; the results are listed in Tables 1, 2 and 3. The equivalent mechanical properties of the braiding yarn were obtained from the micro-scale model. On the other hand, these property values were calculated with two commonly used micromechanical models, namely Chamis' equations [39] :

$$
\begin{aligned}
& E_{11}=V_{\mathrm{fY}} E_{\mathrm{f} 11}+V_{\mathrm{mY}} E_{\mathrm{m}} \\
& E_{22}=E_{33}=-\frac{E_{\mathrm{m}}}{1-\sqrt{V_{\mathrm{fY}}}\left(1-\frac{E_{\mathrm{m}}}{E_{\mathrm{f} 22}}\right)} \\
& G_{12}=G_{13}=-\frac{G_{\mathrm{m}}}{1-\sqrt{V_{\mathrm{fY}}}\left(1-\frac{G_{\mathrm{m}}}{G_{\mathrm{f} 12}}\right)} \\
& G_{23}=-\frac{G_{\mathrm{m}}}{1-\sqrt{V_{\mathrm{fY}}}\left(1-\frac{G_{\mathrm{m}}}{G_{\mathrm{f} 23}}\right)} \\
& v_{12}=v_{13}=V_{\mathrm{fY}} v_{\mathrm{f} 12}+V_{\mathrm{mY}} v_{\mathrm{m}} \\
& v_{23}=\frac{E_{22}}{2 G_{23}}-1 \\
& X_{\mathrm{T}}=X_{\mathrm{fT}} V_{\mathrm{f}}+X_{\mathrm{mT}}\left(1-V_{\mathrm{f}}\right) \\
& X_{\mathrm{C}}=\frac{E_{1}}{v_{12}} \varepsilon_{\mathrm{mT}}\left(1-V_{\mathrm{f}}^{1 / 3}\right)
\end{aligned}
$$

and a concentric cylinder model (CCM), detailed in [40]. The results were compared with the FE results as shown in Table 4. In Table 4 and Eqs. 7-14, $V_{\mathrm{mY}}=1-V_{\mathrm{fY}}\left(V_{\mathrm{fY}}=0.8\right)$ is the volume fraction of the matrix in the yarn and $\varepsilon_{\mathrm{mT}}$ is the ultimate strain of the epoxy matrix. The agreement for most of the values is reasonably good, except for $X_{\mathrm{T}}$. This is discussed later in "Effective Properties of Yarn" section.

Carbon fibre fabrics were initially braided from A-42-12 k fibre tows containing 12,000 fibre filaments. Then, the braids were impregnated with L-20 epoxy resin. Upon curing, samples for tensile testing were cut from panels of A-42 carbon fibre/L-20 epoxy composites thin ply. The dimensions of these samples were $250 \mathrm{~mm} \times 20 \mathrm{~mm} \times 1.5 \mathrm{~mm}$. The ASTM standard D3039 was used as guide in carrying out tensile tests of braided composites. The specimens were tested using an MTS 810 hydraulic material testing system at the crosshead speed of $1 \mathrm{~mm} / \mathrm{min}$ with the gauge length of $150 \mathrm{~mm}$. An axial extensometer was
Table 4 Effective properties of yarn for meso-scale model

\begin{tabular}{llcllll}
\hline & $E_{11} / \mathrm{GPa}$ & $E_{22}=E_{33} / \mathrm{GPa}$ & $G_{12}=G_{13} / \mathrm{GPa}$ & $G_{23} / \mathrm{GPa}$ & $v_{12}=v_{13}$ & $v_{23}$ \\
\hline FE Simulation & 193.93 & 10.90 & 4.59 & 3.65 & 0.18 & 0.35 \\
Chamis' equations & 192.26 & 10.13 & 4.59 & 3.67 & 0.23 & 0.38 \\
$\mathrm{CCM}$ & 191.4 & 9.84 & 4.29 & 3.33 & 0.33 & 0.37 \\
\hline & $X_{\mathrm{T}} / \mathrm{MPa}$ & $X_{\mathrm{C}} / \mathrm{MPa}$ & $Y_{\mathrm{T}} / \mathrm{MPa}$ & $Y_{\mathrm{C}} / \mathrm{MPa}$ & $S_{12} / \mathrm{MPa}$ & $S_{23} / \mathrm{MPa}$ \\
\hline FE simulation & 3388.18 & 1454.48 & 189.69 & 235.08 & 42.20 & 32.08 \\
Chamis' equations & 2540.04 & 1582.27 & & & &
\end{tabular}


attached to the specimen during the tensile test to measure the strain. The braiding angles of the samples were measured before testing as the average value for three different positions.

\section{Results and discussion}

\section{Effective properties of yarn}

Elastic properties as well as the strengths of yarn, obtained by assessing the stress-strain relationships with micro-scale simulations using the developed RUC under different loadings, are shown in Fig. 7 and Table 4.

Apparently, the predicted longitudinal tensile and compressive behaviours are linear due to brittle fibre failure. The stiffness values for matrix- and interfacedominated transverse responses of the tow are lower than tension- and compression fibre-dominated tests in this study. The transverse tensile modulus is apparently larger than those for the shear one. Comparing the predicted shear stress-strain curves for the tow, it is clear that its in-plane shear behaviour is stiffer than the out-of-plane response. This is because of the gradual damage accumulation in the latter case [41]. According to Table 4, the elastic constants obtained with our micro-scale modelling correlate well with those calculated with Eqs. 7-14 and the CCM model. The longitudinal strength values of fibre yarn show a larger discrepancy between the theory and numerical analysis, since the equations for strength prediction are empirical and depend heavily on the mathematical model of fibre arrangement [42]. The disparity can be justified

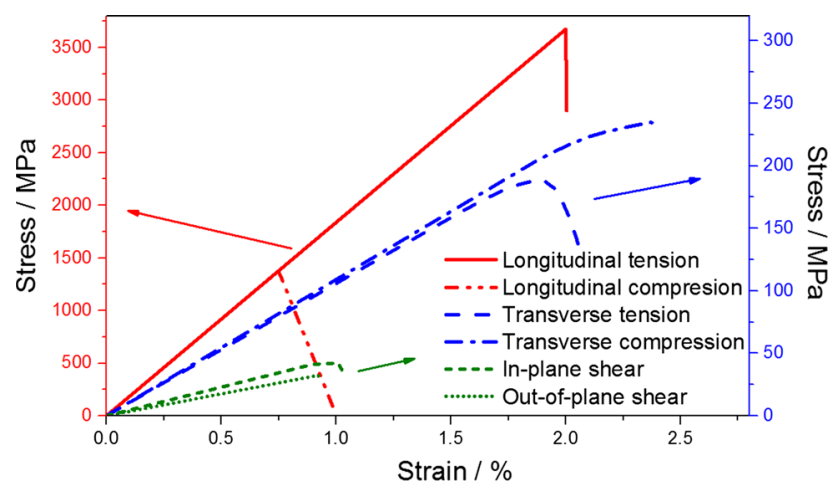

Figure 7 Stress-strain curves for yarn under different loading regimes. employing our previous experimental study [27]: the tensile strength value of yarn, ranges from 2.6 to 3.81 $\mathrm{GPa}$, depending strongly on the chosen gauge length. The average value of the experimental results is approximately $3.29 \mathrm{GPa}$. It is believed that the results based on empirical equations may affect the accuracy of the subsequent FEA [36]. Therefore, in the current study, the values based on the simulation studies are used.

\section{Meso-scale failure analysis of $30^{\circ} \mathrm{bi}$-axial braided RUC}

In this section, the failure analysis of a $30^{\circ}$ bi-axial braided composite was studied as a typical case to verify the developed meso-scale modelling approach. Composite specimens with the same braiding angle $\left(30^{\circ}\right)$ were prepared to compare FE analysis with the experimental data.

Before main simulations, a mesh-convergence study was implemented; its results are presented in Fig. 8. Numbers of elements used for $30^{\circ}$ bi-axial braided RUC varied in this study from 80192 to 112309. Apparently, the non-linear behaviour up to the peak stress value is consistent for different meshes; a post-peak degradation response shows a slight variation. A spread in the ultimate strength is within $2.3 \%$, which is far smaller than a usual error margin in experimental studies. Based on this study, a mesh with 112309 elements was chosen for subsequent simulations.

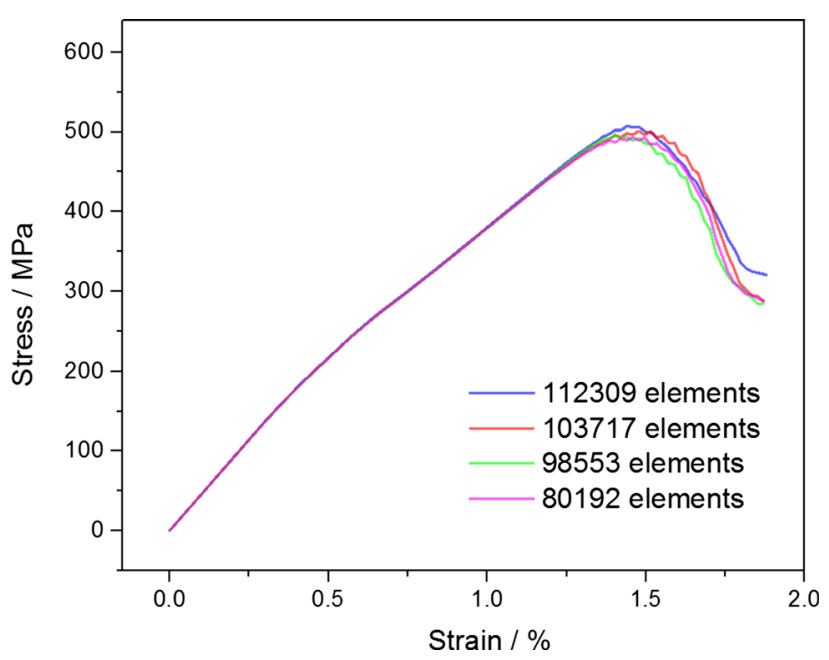

Figure 8 Stress-strain curves for $30^{\circ}$ braided composites RUC in mesh-convergence study. 
Macroscopic stress-strain curves obtained with both numerical and experimental methods are shown in Fig. 9a. The computed initial modulus matches well with the experimentally determined magnitude: the numerical results show a peak of $507.9 \mathrm{MPa}$ at $\sim 1.44 \%$ strain, while the average strength in experiments is $491.1 \mathrm{MPa}$. The computed ultimate strength and strain of meso-scale RUC are in good agreement with the respective experimental values of braided composites.

Evolution of damage variable, $D=1-\bar{E} / E$, under tensile loading (Fig. $9 \mathrm{~b}$ ) indicates the accumulation of damage in the whole unit cell. Here, no failure occurs until point A (at strain of $0.35 \%$ ); after this point, damage variable begins to increase slowly due to initiation of micro-cracks. The cracks propagate slowly till point B. The damage accumulates and grows rapidly after the peak value is finally reached at point $\mathrm{C}$. Evolution of effective damage in experiments is similar to the simulation result. The elastic stage is slightly shorter than that in simulations, indicating that micro-cracks may initiate even at very low strains.

The instantaneous stiffness response, defined as the ratio of differential stress to differential strain $\left(E_{k}=\frac{d \sigma_{k}}{d \varepsilon_{k}}=\frac{\sigma_{k+1}-\sigma_{k}}{\varepsilon_{k+1}-\varepsilon_{k}}, \quad k=1,2,3 \ldots\right)$, is shown in Fig. 9c. experimental noise). However, on processing the data with a fast-Fourier-transform (FFT) low-pass filter (cutoff frequency 40.97), the results show a good match. According to Jia [38], at the initial stage (before point $\mathrm{A}$ ), the obvious variation of instantaneous

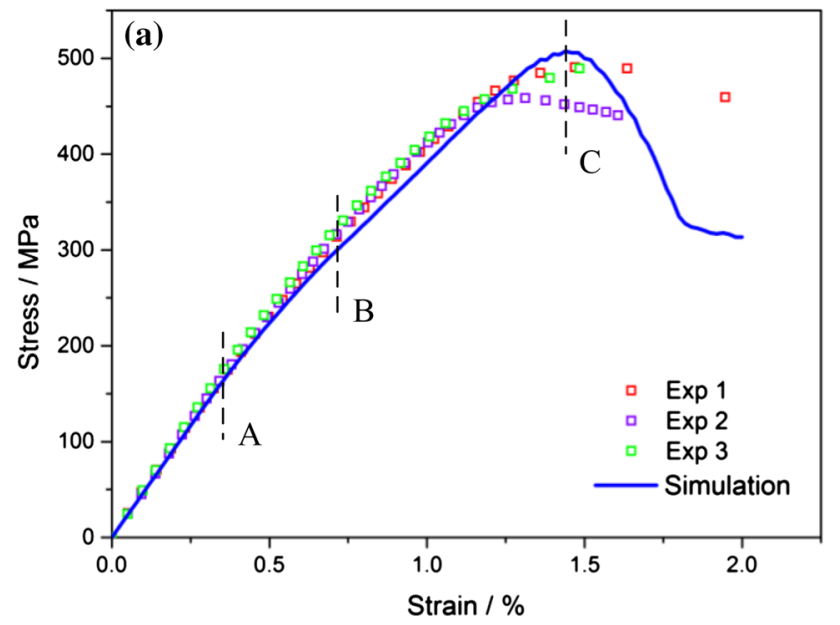
The experimental data show a wide variation (due to

stiffness response is attributed to the initiation of micro-scale cracks. This phenomenon cannot be captured in simulations as no failure occurs according to the chosen constitutive model. After point A, the computed tensile modulus decreases gradually with axial loadings, while the amplitude of experimental instantaneous stiffness varies with a general decreasing trend. It is also reported that as the strain increases during the loading process, the level of the yarn undulation is reduced. The bias yarns are reoriented along the loading direction (straightening effect), which may also result in perceived oscillation of the instantaneous stiffness curve [23]. At higher strain levels, the tangent modulus decreases in experimental and simulation data. This observation is attributed to matrix cracking with the continuous generation of new cracks [9].

In general, the non-linear stress-strain response of braided textile composite is attributed to a complicated character of stress distribution and different failure modes. The Hashin failure criteria capture the necessary failure modes in the meso-scale adequately. Damaged elements (marked in red) are presented in Fig. 10 for three specific strain levels (labelled as A, B and C on the stress-strain curve in Fig. 9). Apparently, element failure initiates first from the interlacing area of bias yarns at strain of $\sim 0.35 \%$, in both matrix tension and compression modes. This implies that matrix cracking starts in the plane parallel to the fibre and between them. Next, failure propagates from the area of undulation to the edge of the yarn at strain of $\sim 0.72 \%$. Correspondingly, damage occurs in pure matrix, which is possibly a
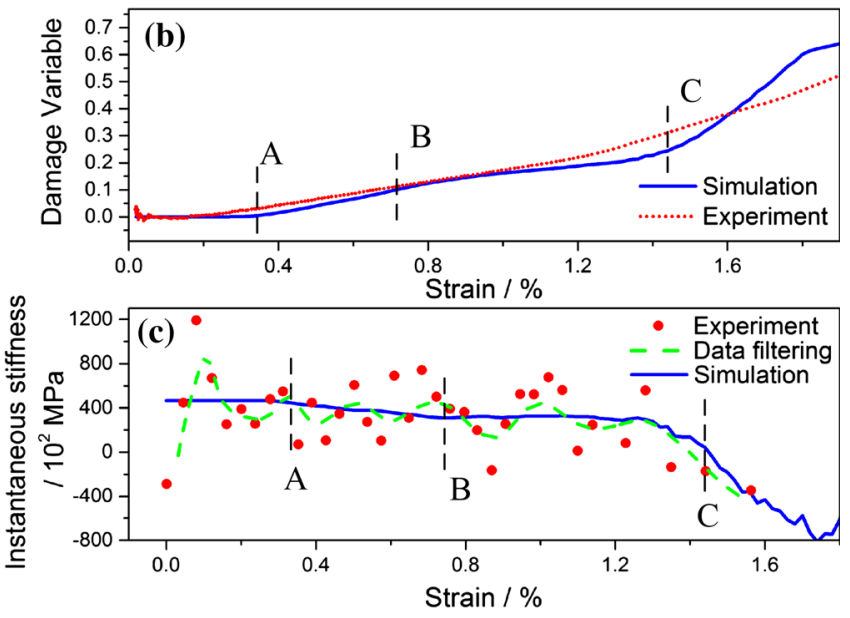

Figure 9 Global stress-strain response (a), evolution of damage variable (b) and instantaneous stiffness (c) of $30^{\circ}$ bi-axial braid in tension. 
Figure 10 Damage contours of $30^{\circ}$ bi-axial braid in tension. (a) Global strain
$0.35 \%$

Matrix Mode
Failure in
tension:

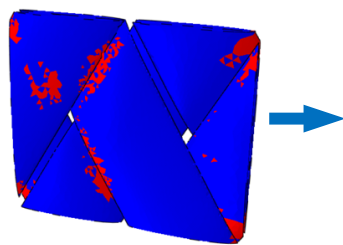

(b) Global strain $0.72 \%$

(c) Global strain $1.44 \%$

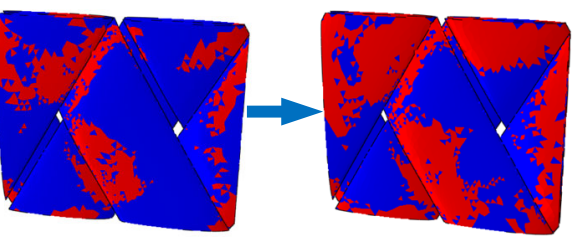
Matrix Mode
Failure in
compression:
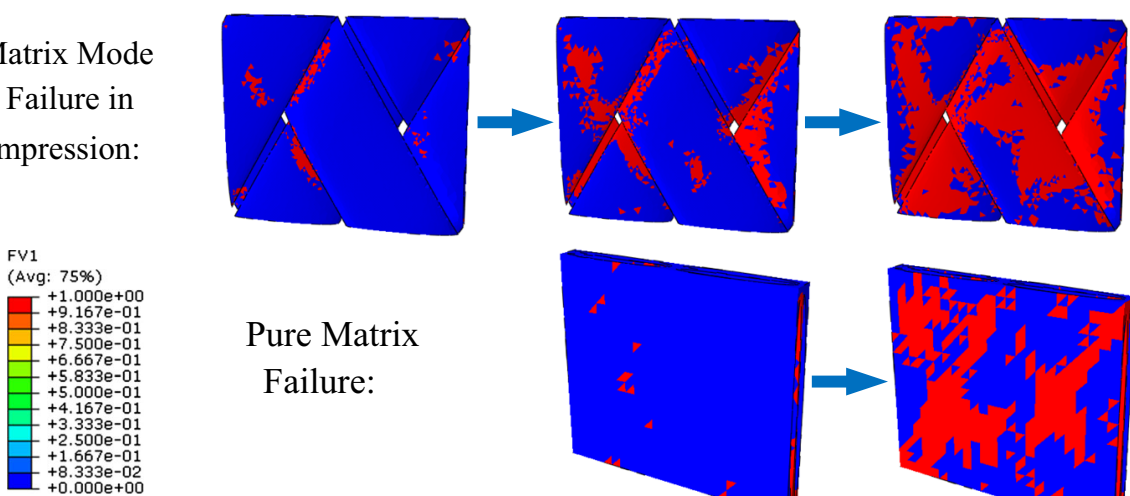

Pure Matrix

Failure:
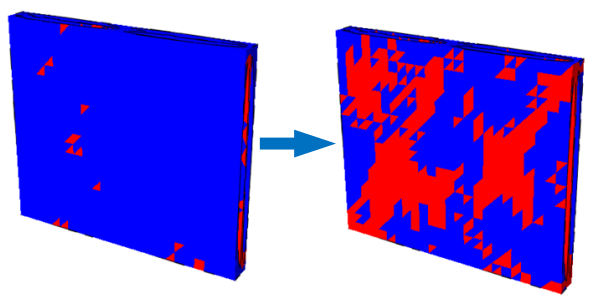

Fibre Mode Failure in tow:

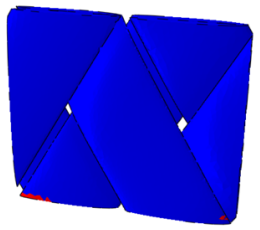

reason of the kink in the stress-strain curve (point B in Fig. 9). Matrix damage is distributed mainly in the yarns' crossing and the undulation regions. At strain of $1.44 \%$, failure of fibre tow in the matrix modes is significant (along with matrix damage), resulting in a drop of the load-carrying capacity (point $C$ in Fig. 9). Interestingly, fibre-mode failure in the tows is not observed even at high strains in the composite.

The stress and strain distributions in the mesoscale RUC (Fig. 11) can be used for analysis of locations, at which failures are likely to occur. It was found that von Mises stress concentrated at the edge of the fibre tow, along the tow direction. The damage, therefore, propagated along the yarn in the direction of the fibres [14]. For braided composites, the matrixfailure mode is attributed to both normal and shear stress components even though the magnitude of the former was observed to be higher than that of the latter. Generally, normal stress are distributed uniformly (Fig. 11), but shear stress concentrates in the interlocked area of the undulated yarns. Under the combination of normal and shear stresses, deformation is severe in the edge region of yarns, where the elements are damaged both in matrix tension and compression modes. According to the strain distribution (Fig. 11), the unit cell mainly undergoes positive strain along the loading direction and negative strain in the regions with undulation due to the Poisson's effect with relatively small shear strain [19].

\section{Meso-scale modelling with different braiding angles}

In this section, we study meso-scale bi-axial unit-cell models under tension to predict the ultimate failure strength and damage progression for different braiding angles. Figure 12 shows the simulated stress-strain curves of RUCs for 10 braiding angles, varying from $15^{\circ}$ to $60^{\circ}$.

As the braiding angle increases, the levels of stiffness and ultimate strength gradually decrease as shown in Fig. 12. For the braiding angle of $15^{\circ}$, the 


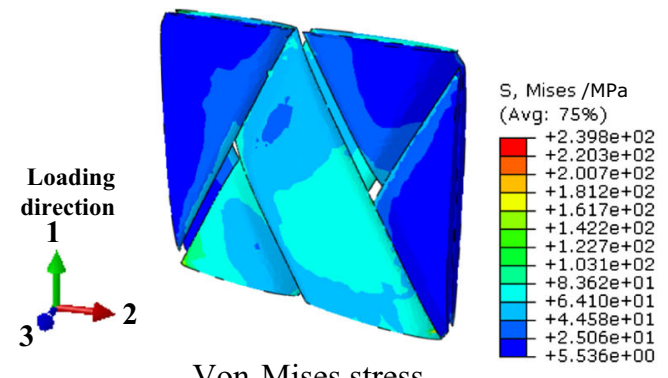

Von-Mises stress in tow

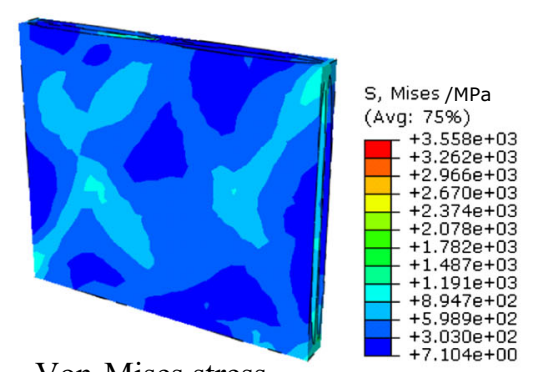

Von-Mises stress

in pure matrix

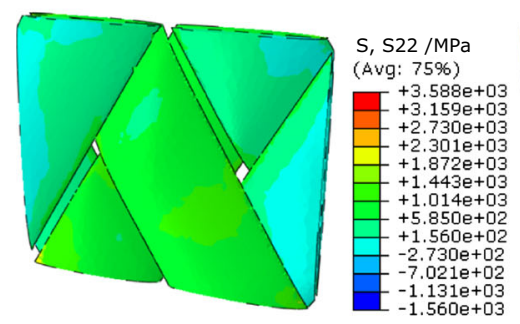

Normal stress $\sigma_{22}$

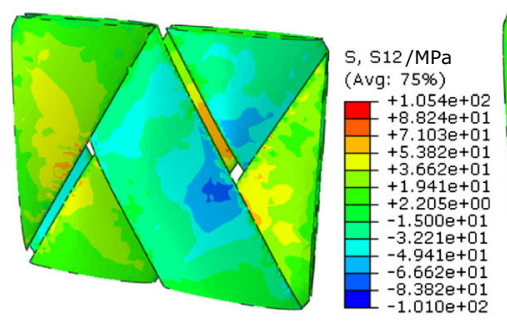

Shear stress $\tau_{12}$

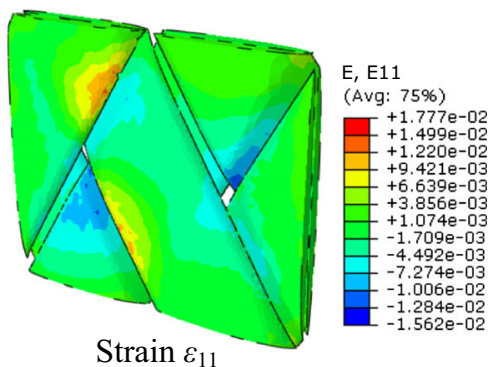

Figure 11 Stress distribution in meso-scale RUC at strain level of $0.73 \%$.

stress-strain behaviour is almost linear up to failure, while stress-strain behaviours for braiding angle larger than $20^{\circ}$ show a more non-linear response, implying progressive damage accumulation reducing the overall stiffness of the component. Interrogation of the specifics of the failure mechanism for braiding angles of $25^{\circ}$ to $40^{\circ}$ demonstrates that it is similar to that for the $30^{\circ}$ case analysed in "Meso-scale failure analysis of $30^{\circ}$ bi-axial braided RUC" section. For the braiding angles larger than $45^{\circ}$, the levels of ultimate failure strain increase. Here, the matrix dominates the overall component's performance, with the minimal contribution from the fibres. For simplicity, braided composites are divided here into three categories based on small $\left(15^{\circ}\right)$, medium $\left(20^{\circ}-45^{\circ}\right)$ and large braiding angles $\left(50^{\circ}-60^{\circ}\right)$. The meso-scale modelling results for two categories are discussed below.

The onset of local damage and its progression in fibre tows and matrix were investigated; the damage contours of the $15^{\circ}$ bi-axial braided composite are
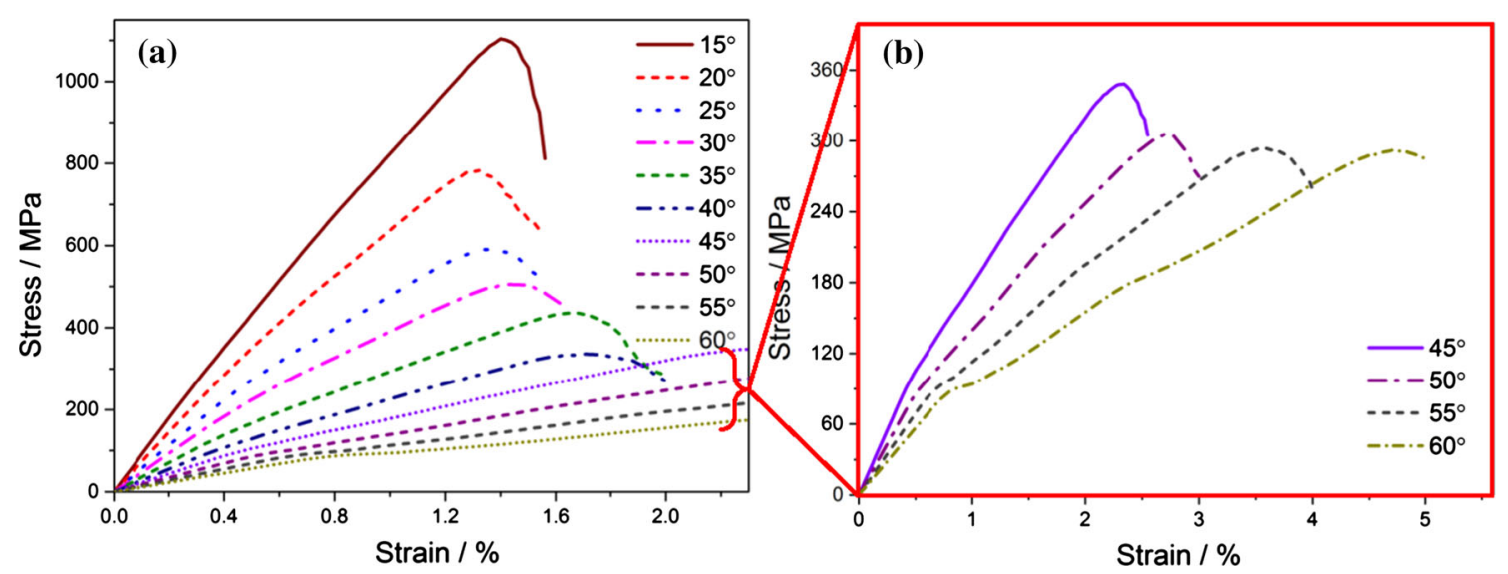

Figure 12 Stress-strain responses of bi-axial braids at 10 different braiding angles (a) and peak strength for structures of larger braiding angles reached at much larger strains $(\mathbf{b})$. 
shown in Fig. 13. Neither fibre nor matrix damage is observed until the strain of $0.4 \%$. First, the onset of damage occurs in the matrix along the interfacial region adjacent to the yarns, then damage accumulates in the matrix, and the fibres rupture in the longitudinal direction at strain of $1.4 \%$, resulting in the sudden decrease of the stress-strain response. A linear character of the macroscopic stress-strain curve indicates that fibres rupture simultaneously with initial fibre failure before the matrix cracking occurs completely in the component. At strain of $1.8 \%$, fibre damage is significant. Comparing this to the case of the braiding angle of $30^{\circ}$, fibre failure in tension plays a key role in the ultimate failure of the composite. Thus, the stress-strain response of $15^{\circ}$ the braided composite has the highest ultimate strength.

As the braiding angle becomes larger, the loadcarrying capacity of the yarns is reduced as reflected in the lower peak stresses. For example, the composite with a braiding angle of $55^{\circ}$ demonstrates a peak stress, which is approximately half of that for the $30^{\circ}$ composite (Fig. 14). This is due to the fact that in the former, matrix damage becomes dominant in contrast to the case of braided composites with lower braiding angles. As observed, the unit cell suffers from large deformation around the yarn edges in the regions with undulation at a strain of $\sim 0.64 \%$. Matrix damage is observed to accumulate rapidly in the tension mode (Fig. 14), both in tows and the matrix block, at strain levels of 1.08 and $3.60 \%$. It is noticed that no fibre damage occurs because the longitudinal stress level is low in this case. Although the matrix in the tension mode is the main damage mechanism, effects of shear interactions were found to cause the matrix failure in the longitudinal direction of the yarn. Hence, the Hashin criteria here clear advantages in accounting for the effects of shear stress $\left(S_{12}\right.$ and $\left.S_{13}\right)$.
Figure 13 Stress-strain response and damage contours of $15^{\circ}$ bi-axial braided RUC (damage in tow includes fibre damage mode, matrix damage in tension and compression modes; pure matrix damage means damage in matrix block).

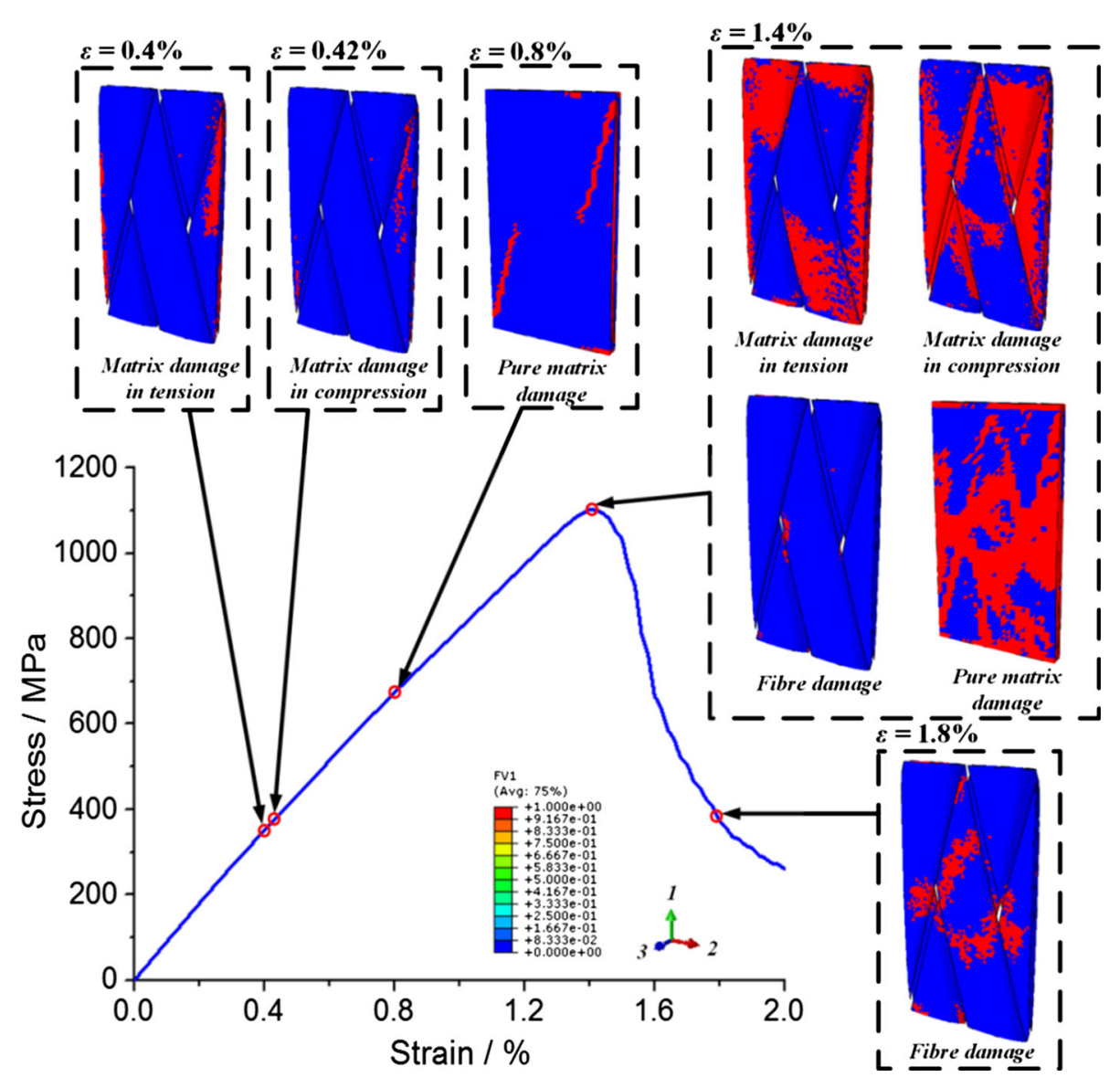


Figure 14 Stress-strain response and damage contours of $55^{\circ}$ bi-axial braided RUC (damage in tow includes matrix damage in tension and compression modes; pure matrix damage means damage in matrix block).

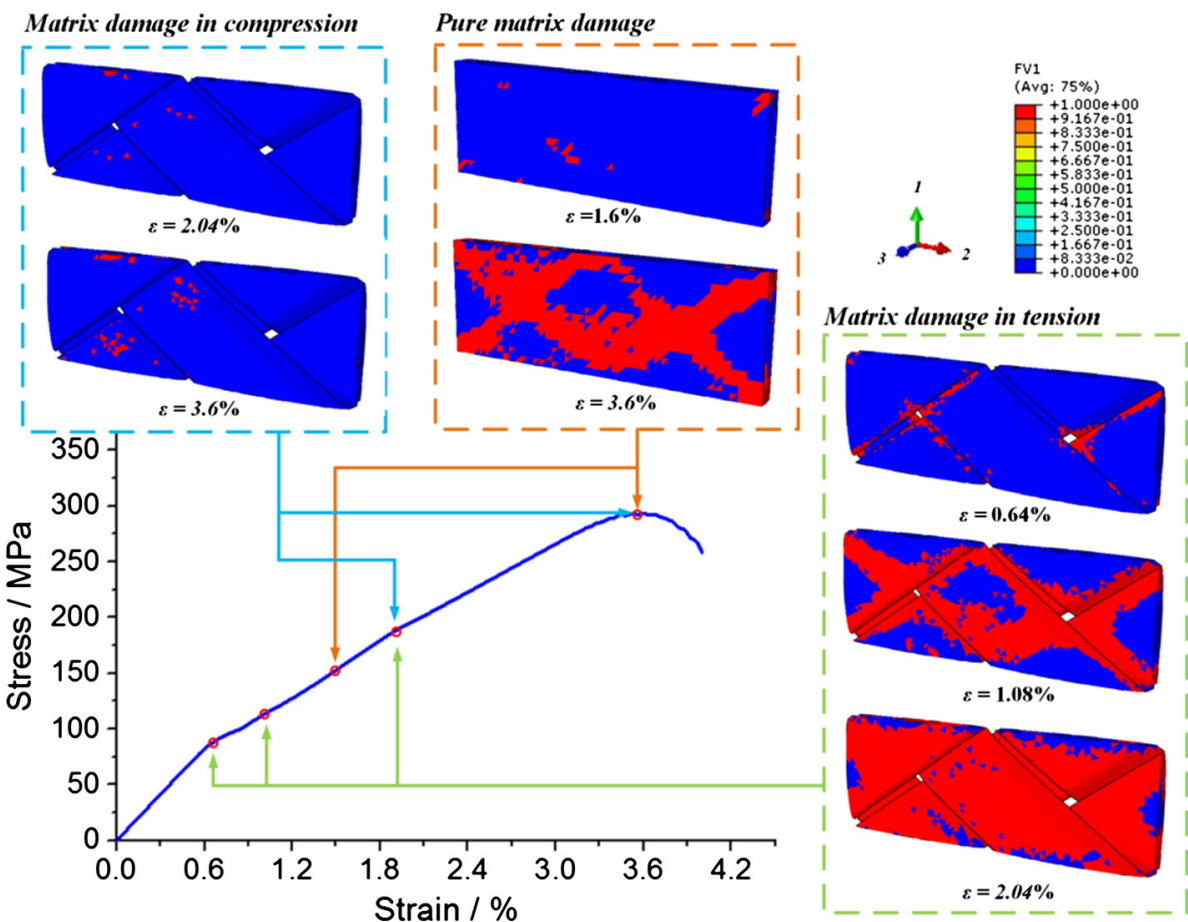

Thus, in summary, it can be concluded that with an increase in the braiding angle, the effects of matrix damage become prominent, causing the material to soften and eventually leading to failure. The failure paths tend to propagate along the tow orientation. Also, tensile strength of the bi-axially braided composite material decreases with the

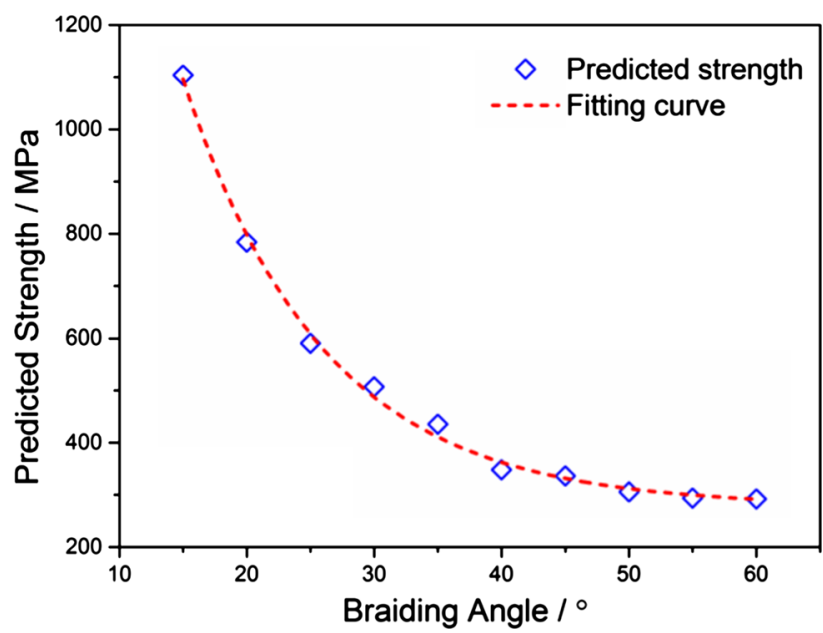

Figure 15 Effect of braiding angle on tensile strength of bi-axial braided RUC. braiding angle (Fig. 15). It is noted that this strength is sensitive to the braiding angle at magnitudes below $40^{\circ}$. Furthermore, with an increase in the braiding angle, the Young's modulus of the biaxial braided unit cell follows a hyperbolic decreasing trend similar to that of strength variation (Fig. 16).

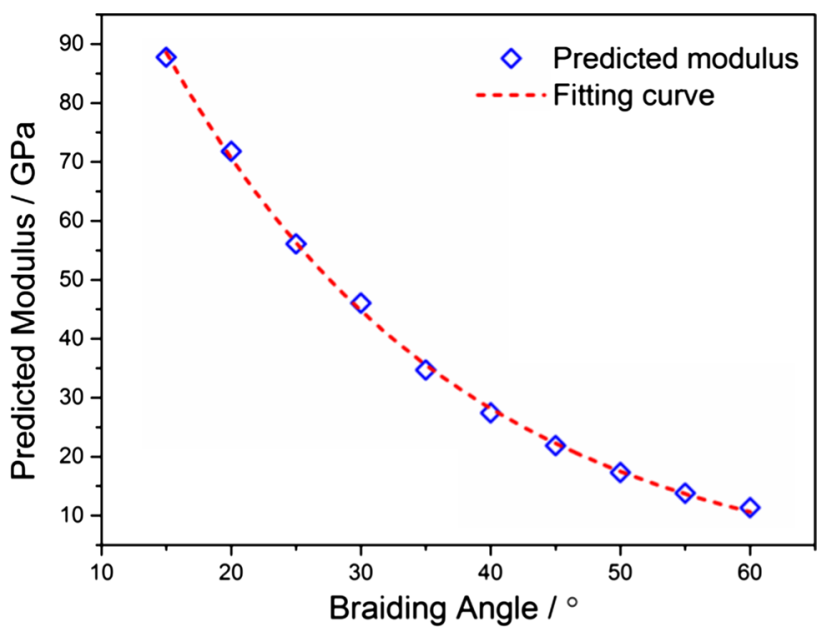

Figure 16 Effect of braiding angle on Young's modulus of biaxial braided RUC. 


\section{Concluding remarks}

To predict deformation characteristics of braided textile-reinforced composites accurately, three essential steps were developed in this work. First, material properties were obtained via experiments to guarantee the quality of input data. Next, a flexible geometrical model was developed, and, finally, appropriate failure criteria were incorporated. The numerical studies were carried out at the micro-scale level followed by those with the meso-scale RUCs of the braided composite. The computed global stressstrain curve was observed to be in a good agreement with the experimental data. In addition, the magnitudes of strength and moduli of bi-axial braided composites were obtained in this work for different braiding angles varying from $15^{\circ}$ to $60^{\circ}$. An overall trend of deformation of the studied composites under longitudinal tension was established.

According to this study, failures in braided composites may be classified into three categories based on the chosen angle of braiding. For small the braiding angles (for example, $15^{\circ}$ ), the composite failed catastrophically, primarily due to fibre damage. For medium braiding angles $\left(20^{\circ}-45^{\circ}\right)$, the stress-strain response indicated matrix cracking and matrix/yarn debonding before fibre breakage. Higher ultimate strain levels were observed for braided composites with large braiding angles $\left(50^{\circ}-60^{\circ}\right)$. This was attributed to the accumulation of matrix-dominated damage in yarns as well as in the pure matrix region. In summary, our computational studies indicate that, with an increase in the braiding angle, yarns suffer from continuous failure during axial tension and the effects of matrix damage become prominent, causing a decrease in ultimate strength and the Young's modulus. It should be noted that the developed model has some limitations in predicting damage evolution of composites, and a more adequate scheme could be based on conservation of fracture energy. So, our computational models are developed further to introduce an account for dynamic characteristics of composite deformation and failure with the aim of addressing applications for sports protective equipment.

\section{Acknowledgements}

$\mathrm{CW}$ is grateful for the financial support by NTU through the PhD scholarship award. The authors are grateful for the technical support by Temasek Laboratory@NTU and Aerospace Lab in the School of MAE at NTU, Singapore.

\section{References}

[1] Tatar Y, Ramazanoglu N, Camliguney AF, Karadag Saygi E, Cotuk HB (2014) The effectiveness of shin guards used by football players. J Sport Sci Med 13:120-127

[2] Salvi AG, Waas AM, Caliskan A (2008) Energy absorption and damage propagation in $2 \mathrm{D}$ triaxially braided carbon fiber composites: effects of in situ matrix properties. J Mater Sci 43(15):5168-5184. doi:10.1007/s10853-008-2684-0

[3] Sun J, Zhou G, Zhou C (2015) Microstructure and mechanical properties of 3D surface-core 4-directional braided composites. J Mater Sci 50(22):7398-7412. doi:10. 1007/s10853-015-9297-1

[4] Wan Y, Wang Y, Gu B (2015) Finite element prediction of the impact compressive properties of three-dimensional braided composites using multi-scale model. Compos Struct 128:381-394

[5] Phadnis VA, Makhdum F, Roy A, Silberschmidt VV (2013) Drilling in carbon/epoxy composites: experimental investigations and finite element implementation. Compos Part A Appl Sci Manuf 47:41-51

[6] Bogdanovich AE (2006) Multi-scale modeling, stress and failure analyses of 3-D woven composites. J Mater Sci 41(20):6547-6590. doi:10.1007/s10853-006-0197-2

[7] Ivanov DS, Baudry F, Van Den Broucke B, Lomov SV, Xie H, Verpoest I (2009) Failure analysis of triaxial braided composite. Compos Sci Technol 69(9):1372-1380

[8] Xiao X, Kia HG, Gong XJ (2011) Strength prediction of a triaxially braided composite. Compos Part A Appl Sci Manuf 42:1000-1006

[9] Fang GD, Jun L, Baolai W (2009) Progressive damage and nonlinear analysis of 3D four-directional braided composites under unidirectional tension. Compos Struct 89:126-133

[10] Prabhakar P, Waas AM (2013) Interaction between kinking and splitting in the compressive failure of unidirectional fiber reinforced composites. Compos Struct 98:85-92

[11] Binienda WK, Li X (2010) Mesomechanical model for numerical study of two-dimensional triaxially braided composite. J Eng Mech 136:1366-1379

[12] Song S, Waas AM, Shahwan KW, Faruque O, Xiao X (2008) Compression response of $2 \mathrm{D}$ braided textile composites: single cell and multiple cell micromechanics based strength predictions. J Compos Mater 42(23):2461-2482

[13] Zhang C, Binienda WK, Goldberg RK, Kohlman LW (2014) Meso-scale failure modeling of single layer triaxial braided 
composite using finite element method. Compos Part A Appl Sci Manuf 58:36-46

[14] Mao JZ, Sun XS, Ridha M, Tan VBC, Tay TE (2013) A modeling approach across length scales for progressive failure analysis of woven composites. Appl Compos Mater 20:213-231

[15] Ernst G, Vogler M, Hühne C, Rolfes R (2010) Multiscale progressive failure analysis of textile composites. Compos Sci Technol 70:61-72

[16] Lomov SV, Ivanov DS, Verpoest I, Zako M, Kurashiki T, Nakai H, Hirosawa S (2007) Meso-FE modelling of textile composites: road map, data flow and algorithms. Compos Sci Technol 67:1870-1891

[17] Llorca J, González C, Molina-Aldareguía JM, Segurado J, Seltzer R, Sket F, Canal LP (2011) Multiscale modeling of composite materials: a roadmap towards virtual testing. Adv Mater 23:5130-5147

[18] Cai Y, Sun H (2013) Prediction on viscoelastic properties of three-dimensionally braided composites by multi-scale model. J Mater Sci 48(19):6499-6508. doi:10.1007/s10853013-7524-1

[19] Bednarcyk B, Stier B, Simon JW, Reese S, Pineda EJ (2015) Meso- and micro-scale modeling of damage in plain weave composites. Compos Struct 121:258-270

[20] Zhang C, Binienda WK (2014) Numerical analysis of freeedge effect on size-influenced mechanical properties of single-layer triaxially braided composites. Appl Compos Mater 21:841-859

[21] Zhang DY, Waas AM, Yen CF (2015) Progressive damage and failure response of hybrid 3D textile composites subjected to flexural loading, part I: experimental studies. Int J Solid Struct 75-76:309-320

[22] Zhang DY, Waas AM, Yen CF (2015) Progressive damage and failure response of hybrid 3D textile composites subjected to flexural loading, part II: mechanics based multiscale computational modeling of progressive damage and failure. Int J Solid Strut 75-76:321-335

[23] Xu L, Jin CZ, Kyu Ha S (2014) Ultimate strength prediction of braided textile composites using a multi-scale approach. J Compos Mater. doi:10.1177/0021998314521062

[24] Zhong S, Guo L, Liu G, Lu H, Zeng T (2015) A continuum damage model for three-dimensional woven composites and finite element implementation. Compos Struct 128:1-9

[25] Zhang C, Li N, Wang W, Binienda WK, Fang H (2015) Progressive damage simulation of triaxially braided composite using a 3D meso-scale finite element model. Compos Struct 125:104-116

[26] Miravete A, Bielsa JM, Chiminelli A, Cuartero J, Serrano S, Tolosana N, de Villoria RG (2006) 3D mesomechanical analysis of three-axial braided composite materials. Compos Sci Technol 66:2954-2964

[27] Ji X, Wang C, Francis BAP, Chia ESM, Zheng L, Yang J, Chen Z (2015) Mechanical and interfacial properties characterisation of single carbon fibres for composite applications. Exp Mech 55:1057-1065

[28] Wang C, Ji X, Roy A, Silberschmidt VV, Chen Z (2015) Shear strength and fracture toughness of carbon fibre/epoxy interface: effect of surface treatment. Mater Des 85:800-807

[29] McWilliams B, Dibelka J, Yen CF (2014) Multi scale modeling and characterization of inelastic deformation mechanisms in continuous fiber and 2D woven fabric reinforced metal matrix composites. Mater Sci Eng A 618:142-152

[30] Huang YC, Jin KK, Ha SK (2008) Effects of fiber arrangement on mechanical behavior of unidirectional composites. J Compos Mater 42(18):1851-1871

[31] Xia Z, Zhang Y, Ellyin F (2003) A unified periodical boundary conditions for representative volume elements of composites and applications. Int $\mathrm{J}$ Solids Struct 40:1907-1921

[32] Ji X, Khatri AM, Chia ES, Cha RK, Yeo BT, Joshi SC, Chen Z (2013) Multi-scale simulation and finite-element-assisted computation of elastic properties of braided textile reinforced composites. J Compos Mater 48:931-949

[33] Song S, Waas AM, Shahwan KW, Xiao X, Faruque O (2007) Braided textile composites under compressive loads: modeling the response, strength and degradation. Compos Sci Technol 67:3059-3070

[34] Zhang C, Binienda WK (2014) A meso-scale finite element model for simulating free-edge effect in carbon/epoxy textile composite. Mech Mater 76:1-19

[35] Garnich MR, Akula VMK (2009) Review of degradation models for progressive failure analysis of fiber reinforced polymer composites. Appl Mech Rev 62:010801

[36] Li X, Binienda WK, Goldberg RK (2011) Finite-element model for failure study of two-dimensional triaxially braided composite. J Aerosp Eng 24:170-180

[37] Christensen RM (2007) A comprehensive theory of yielding and failure for isotropic materials. J Eng Mater Technol 129(2):173-181

[38] Hashin Z (1980) Failure criteria for unidirectional fibre composites. J Appl Mech 47:329-334

[39] Chamis CC (1989) Mechanics of composite materials: past, present and future. J Compos Technol Res 11:3-14

[40] Pankow M, Waas A, Yend C, Ghiorse S (2009) A new lamination theory for layered textile composites that account for manufacturing induced effects. Compos Part A Appl Sci Manuf 40(12):1991-2003 
[41] Jia X, Xia Z, Gu B (2013) Nonlinear viscoelastic multi-scale repetitive unit cell model of $3 \mathrm{D}$ woven composites with damage evolution. Int J Solids Struct 50:3539-3554
[42] Cox BN, Davis JB (2000) Braided composites for energy absorption under tensile loading. J Mater Sci 35(14): 3467-3478. doi:10.1023/A:1004888824424 